\title{
Corrigendum: Climate Driven Changes in Timing, Composition and Magnitude of the Baltic Sea Phytoplankton Spring Bloom
}

\section{OPEN ACCESS}

Edited and reviewed by:

Michelle Jillian Devlin

Centre for Environment, Fisheries and

Aquaculture Science (CEFAS),

United Kingdom

${ }^{*}$ Correspondence: Monika Winder monika.winder@su.se

Specialty section This article was submitted to Marine Ecosystem Ecology, a section of the journal Frontiers in Marine Science

Received: 04 November 2020 Accepted: 11 November 2020 Published: 27 November 2020

Citation:

Hjerne O, Hajdu S, Larsson U, Downing AS and Winder M (2020) Corrigendum: Climate Driven Changes in Timing, Composition and Magnitude of the Baltic Sea Phytoplankton Spring

Bloom. Front. Mar. Sci. 7:626132. doi: 10.3389/fmars.2020.626132

\author{
Olle Hjerne ${ }^{1}$, Susanna Hajdu ${ }^{1}$, Ulf Larsson ${ }^{1}$, Andrea S. Downing ${ }^{1,2}$ and Monika Winder ${ }^{1 *}$ \\ ${ }^{1}$ Department of Ecology, Environment and Plant Sciences, Stockholm University, Stockholm, Sweden, ${ }^{2}$ Stockholm \\ Resilience Centre, Stockholm University, Stockholm, Sweden
}

Keywords: phytoplankton spring bloom, Baltic Sea, phenology, species composition, climate change, diatom, dinoflagellate, Mesodinium rubrum

\section{A Corrigendum on}

Climate Driven Changes in Timing, Composition and Magnitude of the Baltic Sea Phytoplankton Spring Bloom

by Hjerne, O., Hajdu, S., Larsson, U., Downing, A. S., and Winder, M. (2019). Front. Mar. Sci. 6:482. doi: 10.3389/fmars.2019.00482

In the original article, there was a mistake in Figure 6A as published. This figure shows the regression analysis results of group composition at the offshore station BY31 and not at the coastal station B1 as stated in the text. The corrected Figure 6A appears below.

The authors apologize for this error and state that this does not change the scientific conclusions of the article in any way. The original article has been updated.

Copyright $\odot 2020$ Hjerne, Hajdu, Larsson, Downing and Winder. This is an open-access article distributed under the terms of the Creative Commons Attribution License (CC BY). The use, distribution or reproduction in other forums is permitted, provided the original author(s) and the copyright owner(s) are credited and that the original publication in this journal is cited, in accordance with accepted academic practice. No use, distribution or reproduction is permitted which does not comply with these terms. 


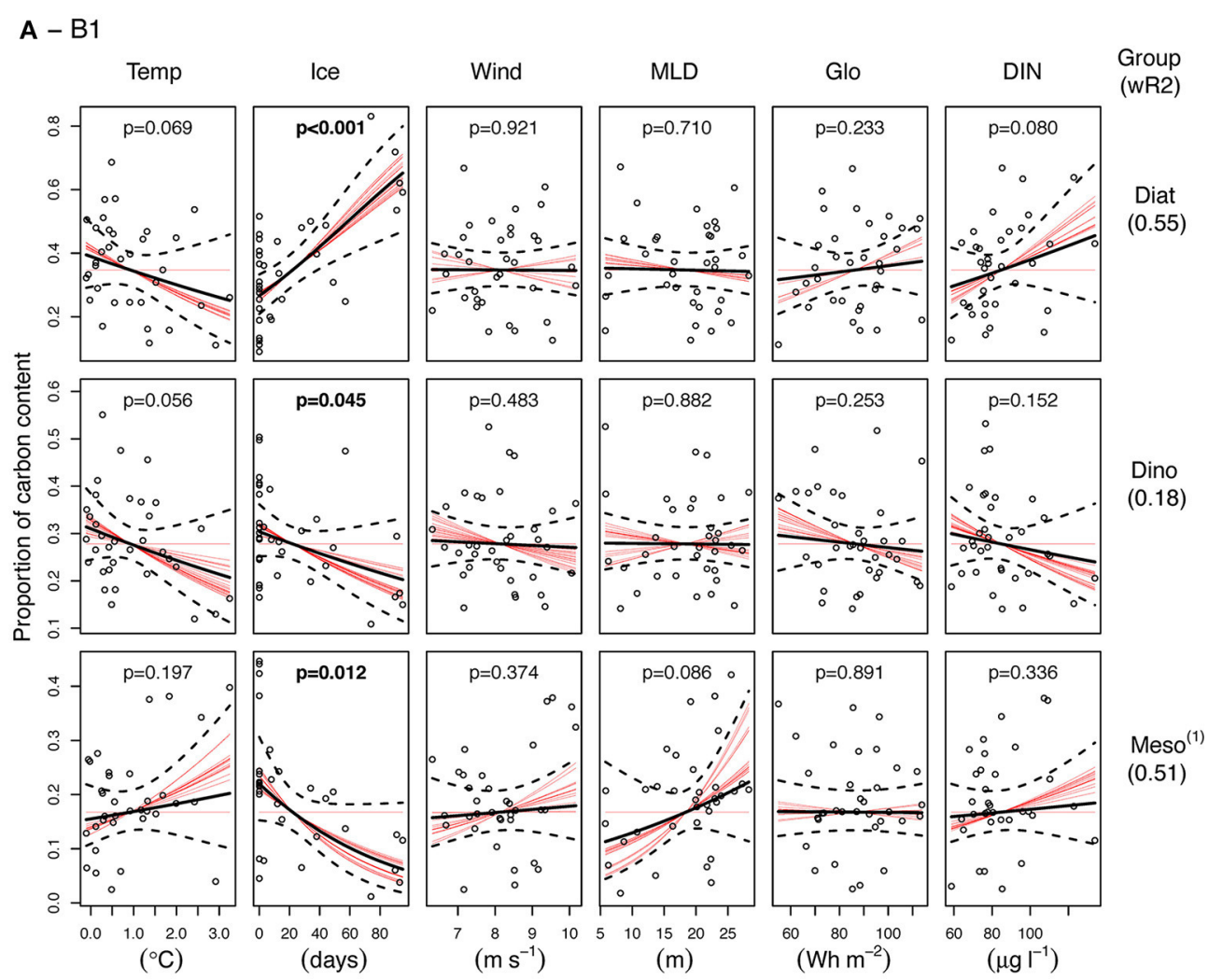

B - BY31
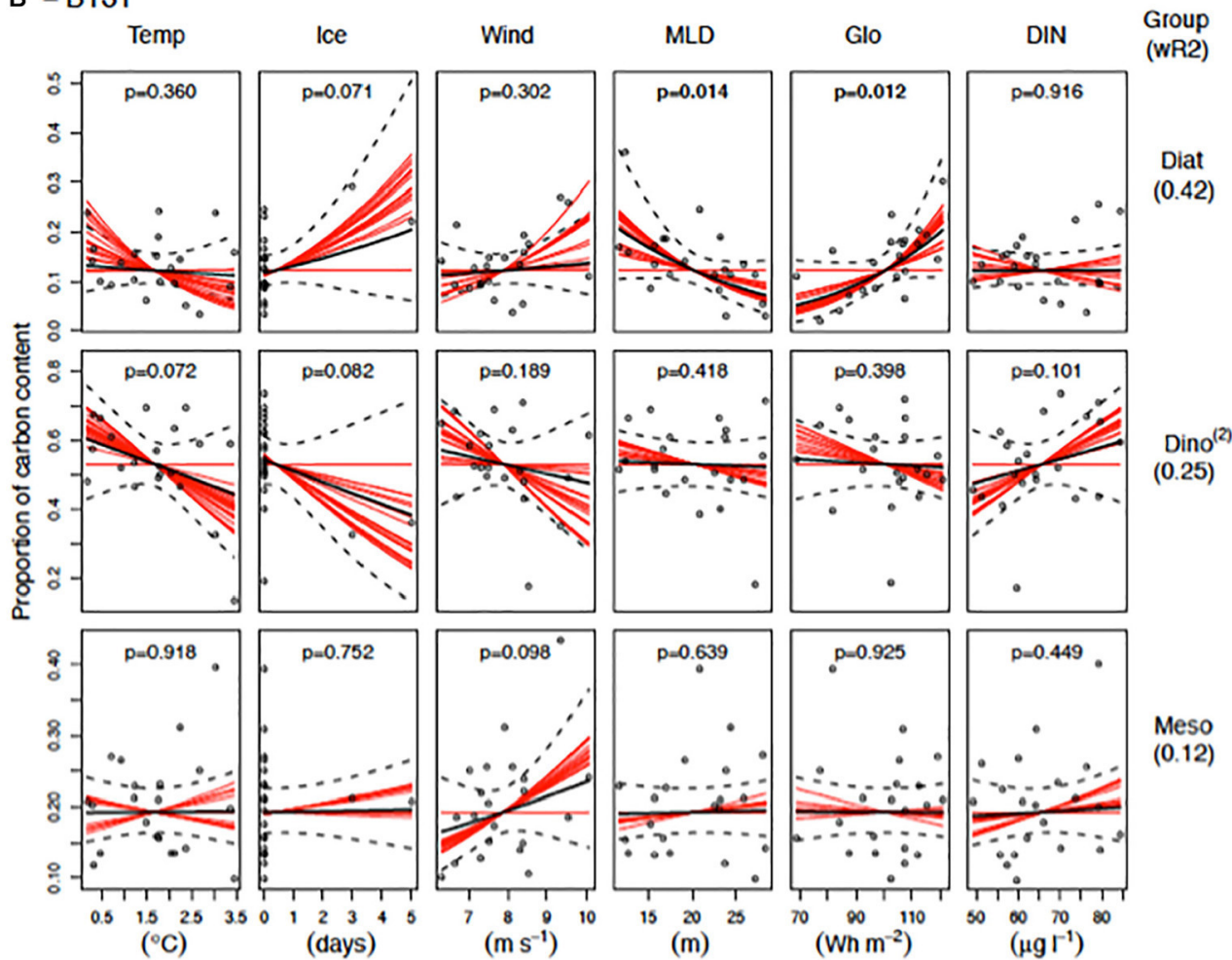

FIGURE 6 | Continued 
FIGURE 6 | Regression analysis results of group composition (the relative contribution of diatoms, dinoflagellates and Mesodinium rubrum to the average biomass in March-May) at the coastal station (A, B1) and offshore station (B, BY31) in the northern Baltic Proper. The solid and dashed black lines are the fitted regression lines and the $95 \%$ confidence intervals of the average models, respectively. Red lines are the fitted regression lines of the individual models that contribute to the average model. If the slopes of a predictor are either all positive or negative in the individual models there is strong support for an effect of the predictor, while different signs or lack of slope indicate uncertainty of its effect. The black circles represent the partial residuals from the average model. $p$-values within the panels and the weighted R2 (wR2) values are based on the AICc weights. Model results should be interpreted with care when model validation plots indicate violation to the model assumptions: (1) Possibly slightly non-normal distribution of residuals (long lower tail), (2) Just significant negative temporal autocorrelation at lag 3 and higher variance of residuals at low fitted values. 